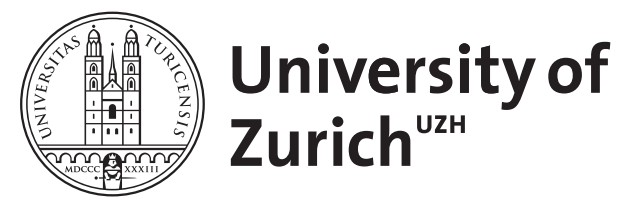

\title{
On the scope of externalities in experimental markets
}

Bartling, Björn ; Valero, Vanessa ; Weber, Roberto A

\begin{abstract}
We study how the scope of negative externalities from market activity affects the willingness of market actors to exhibit social responsibility. Using the laboratory experimental paradigm introduced by Bartling et al. (Q J Econ 130(1):219-266, 2015), we compare the voluntary internalization of negative social impacts by market actors in cases where the negative externality is diffused among many subjects or is concentrated on a single subject. We (1) replicate earlier results demonstrating substantial degrees of market social responsibility and (2) find that the willingness of market actors to act pro-socially is only slightly affected by whether the impacts are concentrated or diffused.
\end{abstract}

DOI: https://doi.org/10.1007/s10683-017-9549-9

Posted at the Zurich Open Repository and Archive, University of Zurich ZORA URL: https://doi.org/10.5167/uzh-143638

Journal Article

Accepted Version

Originally published at:

Bartling, Björn; Valero, Vanessa; Weber, Roberto A (2019). On the scope of externalities in experimental markets. Experimental Economics, 22(3):610-624.

DOI: https://doi.org/10.1007/s10683-017-9549-9 


\title{
On the Scope of Externalities in Experimental Markets
}

\author{
Björn Bartling \\ University of Zurich
}

\author{
Vanessa Valero \\ University of Zurich
}

\author{
Roberto Weber \\ University of Zurich
}

June $9,2017^{*}$

Forthcoming in: Experimental Economics

\begin{abstract}
We study how the scope of negative externalities from market activity affects the willingness of market actors to exhibit social responsibility. Using the laboratory experimental paradigm introduced by Bartling, Weber \& Yao (2015), we compare the voluntary internalization of negative social impacts by market actors in cases where the negative externality is diffused among many subjects or is concentrated on a single subject. We (i) replicate earlier results demonstrating substantial degrees of market social responsibility and (ii) find that the willingness of market actors to act pro-socially is only slightly affected by whether the impacts are concentrated or diffused.
\end{abstract}

JEL Classification: C92, D62, M14

Keywords: Negative externalities, scope of externalities, social responsibility, market experiments

\footnotetext{
* Department of Economics, Blümlisalpstrasse 10, CH-8006 Zurich, e-mail: bjoern.bartling@econ.uzh.ch, vanessa.valero@econ.uzh.ch, roberto.weber@econ.uzh.ch. The authors gratefully acknowledge financial support from the Swiss National Science Foundation (grant number 100018_165943).
} 


\section{Introduction}

Market exchange, while typically value enhancing, also often has the potential to create significant negative externalities, such as environmental pollution. Traditional economic policies-for instance, Pigouvian taxes-may fail to correct these market failures, as when policymakers lack information or are subject to lobbying (Bénabou and Tirole, 2010). An important question, therefore, deals with the extent to which market participants exhibit social responsibility and voluntarily internalize externalities, thus providing an alternative possible remedy to the problem of negative external costs from market activity.

To address this question, a growing strand of economic research studies pro-social or ethical behavior in experimental market contexts (e.g., Danz et al. 2012, Falk and Szech 2013, Bartling et al. 2015, Irlenbusch and Saxler 2015, Kirchler et al. 2015, Pigors and Rockenbach 2016, Sutter et al. 2016). While much of this research is recent, the use of laboratory experiments to study the voluntary internalization of externalities extends back to Plott (1983), who conducted - to our knowledge - the first experimental study explicitly focused on behavior in markets with negative externalities. Plott's findings are very clear-behavior closely approximates the predictions of traditional theory that market actors will ignore the impacts of their actions on others. In contrast, the results of more recent studies often find market participants to show substantial concern for the external impacts of their actions. For example, Bartling et al. (2015, henceforth BWY) study a posted-offer market in which buyers and sellers can trade goods with and without externalities. The results reveal, across several varying market settings, that a substantial and fairly stable fraction of market participants exhibit concern for social impact, by forgoing profits to eliminate negative externalities.

One important feature of BWY's design - and of many other papers in the recent literature-is that they study a particular type of externality: each "harmful" product that a consumer purchases yields a large and concentrated negative impact, i.e., on a single person outside the market. However, the scope of real-world market impacts-who is affected by an external cost-may vary considerably. Product externalities may be concentrated, creating significant harm for a small set of people, or they can be diffused and create relatively small individual impacts for a large number of individuals. An example of a highly concentrated impact on a relatively small set of people is the prominent Minamata case in Japan (Harada, 1995). The Chisso Corporation, a Japanese chemical company supplying, among other things, liquid crystal 
for the production of LCDs, released untreated mercury-polluted water into an enclosed bay in Minamata over a period of 36 years between 1932 and 1968. This led to thousands of deaths and victims of disease. The Minamata fishing families, who relied on a locally-sourced seafood-rich diet, bore the costs of such highly concentrated mercury poisoning. A contrasting example of a more diffused negative external impact of market activity is the mercury emissions of the mining industry in Chile, where wastewater is often released into the rivers (Barrios-Guerra, 2004). This results in rapid dilution and flow of much of the mercury into the ocean. While this potentially exposes a much larger number of people living close to coastal waters to pollution than the number of villagers in Minamata Bay, the harm imposed on each individual is much smaller in magnitude. While this contrast is stark, there are numerous other examples of where externalities from similar market activities can create large burdens for small numbers of people or smaller burdens for many more individuals. ${ }^{1}$ However, little is understood about how such variation in the scope of market externalities affects the extent to which market participants are willing to incur costs to mitigate the harm they produce.

There are several reasons to believe that the distinction between concentrated and diffused impacts may be meaningful in eliciting social concern. For instance, a recent experimental study by Schumacher et al. (2016), using a variety of stylized distributional games, finds that pro-social concerns appear to exhibit insensitivity to the number of people affected and, instead, respond mainly to the magnitude of the cost incurred per capita. Social concern in markets may similarly respond to whether external costs are diffused-such that a small cost is imposed on several individuals - or concentrated — such that a much larger impact is imposed on a single individual, as in BWY. Schumacher et al.'s results suggest that, in the former case, the total harm imposed might be neglected, despite being substantial in sum, since subjects solely focus on the magnitude of the per capita harm and largely ignore the number of affected individuals.

While less closely, our research question also relates to a small literature in psychology on “identifiable victims," which indicates that concern for the harm imposed on others might depend

\footnotetext{
${ }^{1}$ For instance, there exist varying forms of pollution (pesticides, radioactive waste, etc.) with differently sized impacts for different numbers of people, as in our example. As another example, overexploitation of a specific resource of value to a relatively small group of people living in a circumscribed area (e.g., a variety of fish relied upon by a local population) has more focused impacts than other similar wider ranging market activities (overfishing in general). Similarly, a firm entirely disregarding safety requirements to cut costs may yield unsafe working conditions for employees at a particular factory (e.g., the Rana Plaza factory collapse in Bangladesh that killed 1135 workers in 2013), in contrast to a firm engaging in lobbying for slightly relaxed labor safety laws and thereby having smaller impacts on potentially many more individual workers.
} 
on the degree to which external impacts fall clearly on a single person or on a less personifiable collective. For example, Small and Loewenstein (2003), Small et al. (2007), and Slovic (2007) demonstrate that individuals exhibit greater concern for more "personalized" victims than for "statistical victims" in laboratory and field experiments. Thus, news stories about workers highly mistreated at a particular factory may have a greater impact on consumer's social concern than ones about firms lobbying to limit worker protections. That is, social concern in markets may similarly respond to whether comparably-sized impacts are felt by single individuals ("personalized") or are diffused over larger numbers of ("statistical") victims.

To address our research question, we employ a version of BWY's market design in which we exogenously vary whether a fixed external harm from market activity is diffused over many people or concentrated on a single person. This provides a clean test of whether the scope of externalities affects pro-social market behavior. While the laboratory environment is a highly stylized one in which to study complex markets, the control it affords allows us to exogenously vary the scope of the external impact, while keeping the total harm produced by external impacts and other features of the market environment constant.

In our market setting, subjects in the roles of buyers and sellers can exchange two types of products that have the same monetary value for buyers but differ in their social impact and in their production cost. A "harmful" product imposes a negative externality on subjects in the passive role of third parties. A "fair" product does not impose an externality, but costs more to produce. As our focus, our treatments vary the scope of the market externality, while holding constant the overall aggregate impact. Specifically, we consider two extreme cases in which the full impact of the externality produced by a market transaction is either borne by a single third party, as in BWY, or in which the same impact is diffused over all six third parties that are linked to a market. Our design allows us to address the important question of how the scope-the number of people affected by an externality and the size of the impacts - affects market participants' social concern. It also allows us to test a possible reason for why the results of Plott (1983), who has highly diffused external market impacts, finds little social concern, while others, such as BWY, find substantially more concern for social impact.

To preview our results, we find that the market share of the fair product is slightly lower when the harm from an externality is diffused over several third parties than when it is concentrated on a single third party, but this difference is relatively small and not robustly statistically 
significant. More precisely, we first replicate the main finding of BWY, who observed a substantial market share for the fair product when the externality is imposed on one person (43 percent in the current paper when the externality is concentrated, compared to 44 percent in BWY). ${ }^{2}$ Thus, our experimental markets do not converge to the competitive equilibrium predicted by traditional theory, in which only the harmful and cheaper-to-produce product is traded. Importantly, this finding holds even in our treatment with diffused harm, where the market share of the fair product amounts to 35 percent, and it stabilizes at levels close to this percentage. That is, even when the externality is diffused over several subjects, markets do not behave as if externalities were irrelevant. Hence, we conclude that, while a more diffused impact seems to lower somewhat market participants' concerns for negative externalities, it does not eliminate or greatly diminish such concern.

The remainder of the paper proceeds as follows. Section 2 describes the experimental design. Section 3 reports our results. Section 4 concludes.

\section{Experimental Design}

Our design is based on the market paradigm introduced by BWY. This involves a posted-offer product market, repeated for 24 periods, in which firms and consumers can trade products with and without negative externalities. Our primary modification is to vary the scope of the externality produced by the exchange of a single product.

\subsection{Market Game}

A market comprises 16 participants: four sellers, six buyers and six third parties. Roles are randomly assigned at the beginning of the study and remain fixed throughout all 24 market periods. At the beginning of a period, each participant receives an initial endowment of $100 .{ }^{3}$ At the end of the experiment, one period is randomly selected to determine payments.

\footnotetext{
${ }^{2}$ We study two different treatments with concentrated harm. In our main treatment, which corresponds to the scope of externalities in BWY, a buyer is randomly matched to a third party in every period of the repeatedly-played market game so that it is not necessarily the same third party that would be harmed in different periods of the game. In an additional treatment, there is a fixed match between a buyer and a third party, so that the externality is directed to the same third party in every period. We find that the market share of the fair product is not different in the two treatments (43 percent in the former vs. 45 percent in the latter treatment).

${ }^{3}$ Payoffs in the experiment were denominated in points and converted to cash at the conclusion of a session at a rate of 5 points $=1 \mathrm{CHF}$.
} 
Buyers and sellers can exchange two types of products, which differ only in their negative impact on third parties and in their production cost. One product ("fair") is socially responsiblei.e., does not produce negative externalities-but costs 20 to produce. The other product ("harmful") creates a negative externality of 60 for third parties, but costs nothing to produce. Both types of products have identical value (50) to the buyer, meaning that a preference for one over the other can only be driven by concern for social impact.

At the beginning of each period, sellers simultaneously select product types (fair or harmful) and prices (between 0 and 50) in a posted-offer market. Once all sellers make their decisions, the resulting offers are publicly revealed to all market participants. Buyers then simultaneously decide whether to buy at most one product. Multiple buyers can buy from the same seller, meaning that an individual seller can sell between 0 and 6 products. ${ }^{4}$ Each seller earns, for each product sold, the difference between the posted price and the production cost. Each buyer earns, if he decides to buy a product, the difference between the product's value of 50 and the price paid.

Third parties can neither sell nor buy, but they can incur losses depending on the nature of products exchanged. Our focus is on two treatments that hold constant the size of a product's externality, but vary who it impacts. In treatment Concentrated, the purchase of a product by a buyer in a period affects one randomly-selected third party, as in BWY. More precisely, if the buyer purchases a harmful product, this imposes a loss of 60 on the selected third party. In treatment Diffused, there is no match between a buyer and a third party. Instead, if a buyer purchases a harmful product, this imposes a loss of 10 on each of the six third parties associated with that market. Importantly, the design holds constant the total loss imposed on passive third parties by a harmful product purchase across the two treatments -0 for a fair product and 60 for a harmful product. Therefore, these two treatments-Concentrated and Diffused-allow us to test whether, starting from the design in BWY, making the impact of an externality more diffused among an impacted population significantly diminishes the degree of concern for social impact exhibited by market participants.

\footnotetext{
${ }^{4}$ The main design change relative to BWY — other than the variation of the scope of externality-is the removal of the sellers' capacity constraints, which limited sellers to a single unit in the study by BWY. This change substantially increases the competition among sellers, since a single seller can now serve the entire market. We also made one additional minor change from the design in BWY, setting the production costs for the fair and harmful products to, respectively, 0 and 20, in contrast with 0 and 10 in BWY.
} 
In addition, we conducted a further experimental treatment to ensure that the harm in the Concentrated treatment is actually perceived to be concentrated on a single individual. Note that in the Concentrated treatment based on BWY and described above, the buyer's product choice impacts a different, randomly selected, third party in every period. It is thus possible that a buyer perceives the choice of a harmful product as causing a loss of 10 in expectation for each third party. As a consequence, the harm imposed might not be perceived as concentrated but as "diffused in expectation." To ensure that subjects perceive the negative impact imposed by market activity as truly concentrated on a single individual, we conducted a third treatment, Concentrated \& Fixed, in which the impact of a specific buyer's purchasing decision harms the same third party in all 24 periods of the experiment. This treatment allows us to observe whether a greater concentration of harm on a single, more personifiable, individual influences the degree of concern exhibited by market participants.

\subsection{Procedures}

We conducted 10 independent markets for each treatment. In total, 480 participants took part in our study. Subjects were students from the University of Zurich and the Swiss Federal Institute of Technology. We implemented the experiment using z-Tree (Fischbacher 2007) and recruitment using h-Root (Block et al. 2014).

Within each market, participants were randomized to roles by drawing a number at the beginning of a session, and then received written instructions followed by control questions. The experimental instructions are provided in the Appendix. An audio file with a summary of the instructions was played before the experiment, to establish common information regarding the market rules. Each session lasted approximately 1.5 hours. On average, participants earned CHF 39 (about 38 USD), which included a show up fee of CHF 15.

\section{Results}

Our main focus is the comparison of the market outcomes in treatment Concentrated, where the externality from trading the harmful product is imposed on a single person with the market outcomes in treatment Diffused, where the externality from trading the harmful product is diffused over several people. We additionally compare treatment Concentrated, where the externality 
caused by a buyer's purchase of a harmful product is imposed on a different person each period, to a third treatment, Concentrated \& Fixed, where the externality is imposed on the same person each period.

Our analysis focuses on the 99 percent of cases in which buyers made a trade and excludes the 1 percent of cases in which buyers did not make a purchase. Our focus is on the market share of fair products in the different treatments, though we also consider prices. Additionally, we examine the individual behavior of buyers, by conducting structural estimation of parameters in a simple utility framework in which buyers care about their own earnings and about the social cost imposed by their market behavior.

\subsection{Concentrated versus Diffused}

We first compare the market shares of the fair product between treatments Concentrated and Diffused. This measures the percentage of the maximum possible impact of negative externalities that is mitigated by market actors producing and purchasing the "fair" product instead of the "harmful" product. Note that the prediction of the traditional model, assuming narrow self-interest among all market participants, is that the fair product will be absent.

Figure 1 shows market shares. Across all periods, these shares are 43 percent in treatment Concentrated and 34 percent in treatment Diffused. While these market shares are ordered in the manner one would expect when assuming less concern for more diffused harm, the differences are statistically insignificant using a two-sided Wilcoxon rank-sum test, either at the market $(p=0.13)$ or buyer $(p=0.58)$ level. Moreover, the market share for fair products appears generally stable across rounds in both the Concentrated and Diffused treatments. Similarly to BWY, market participants regularly trade fair products at their own expense-between one-third and one-half of the time-to avoid imposing externalities on society, both in treatments Concentrated and Diffused. This indicates that market participants' willingness to behave socially responsibly does not strongly depend on the scope of the resulting externalities. 


\section{Figure 1 - Market shares of fair products (Concentrated vs. Diffused)}

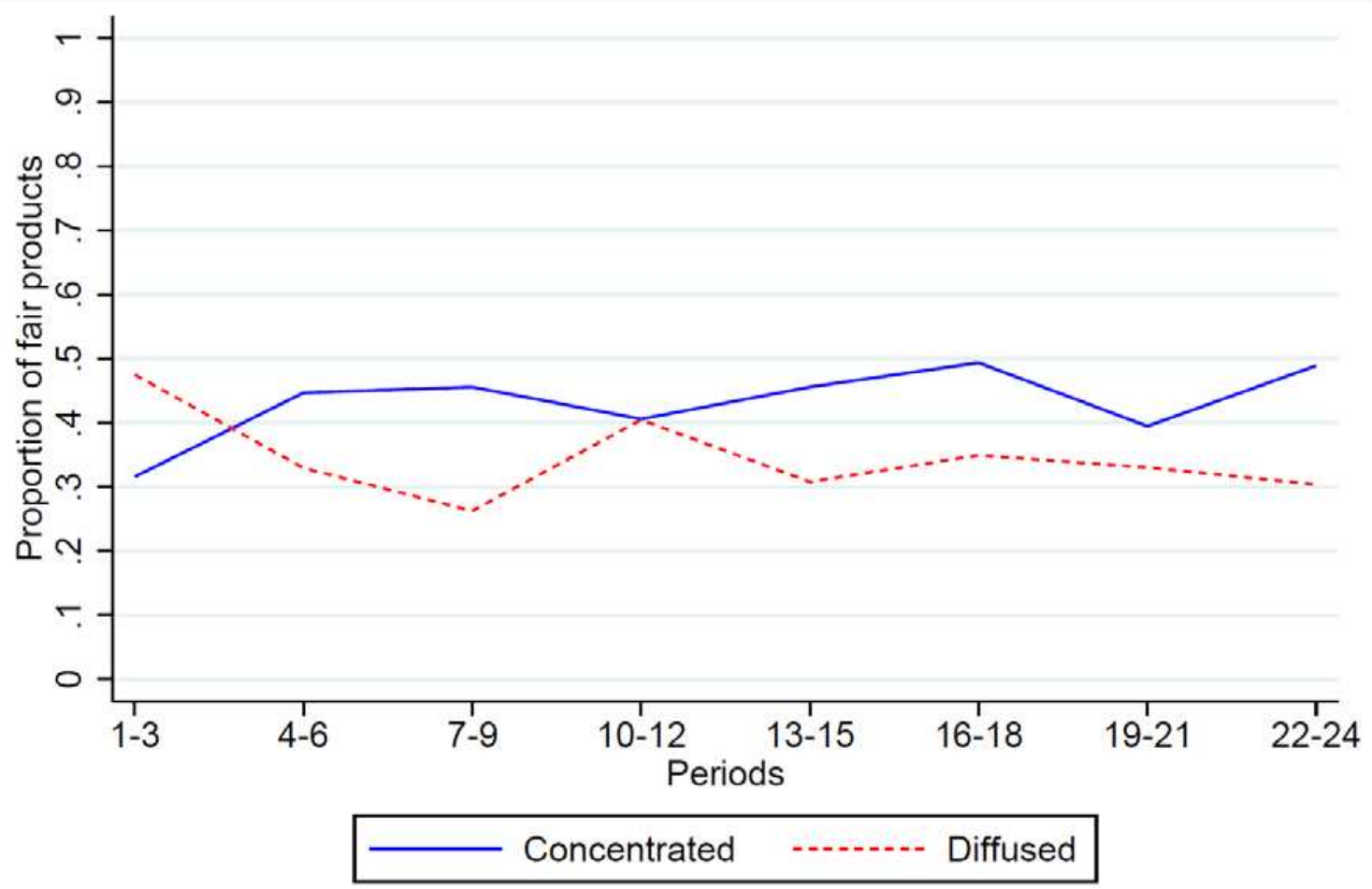

Data are aggregated in three-period blocks to smooth random variation across periods.

We also estimated random-effects probit models of the decision to buy a fair product, which are reported in Table 1. Treatment Concentrated serves as the omitted category in all regression models. Model 1 utilizes data from all 24 periods, while we restrict the analysis to periods 13-24 in model 2. Focusing on the second half of the study serves as a robustness check in which we limit the analysis to those periods where behavior is likely to have stabilized following any initial learning and adjustment. Indeed, Figure 1 indicates that behavior is generally stable in both treatments following some initial adjustment, and that the treatment difference is generally consistent in periods 13 to 24 . The table shows that the coefficient of the indicator variable for treatment Diffused is negative and significant at the five percent level in model 1 and at the one percent level in model 2. Models 3 and 4 consider again either all periods or only the second half of the experiment, respectively, and additionally include Period as an explanatory variable and its interaction with the treatment variable. In model 3, the coefficient for the interaction term is negative and significant, indicating that the main source of treatment effects is the slight differences in time trends apparent in Figure 1. However, as model 4 reveals, these time trends are 
small and insignificant in the second half of the experiment, and the resulting difference in levels of socially responsible behavior-identified by the negative coefficient on the treatment variableis marginally significant, at the ten percent level.

\section{Table 1 - Random-effects probit regression of the fair choice}

\begin{tabular}{lcccc}
\hline \hline & $(1)$ & $(2)$ & $(3)$ & $(4)$ \\
\hline Diffused & $-0.324 * *$ & $-0.621^{* * *}$ & 0.109 & $-0.801^{*}$ \\
& $(0.146)$ & $(0.205)$ & $(0.198)$ & $(0.426)$ \\
Period & & & $0.019 *$ & -0.008 \\
& & & $(0.010)$ & $(0.019)$ \\
Diffused x Period & & & $-0.035^{* *}$ & 0.010 \\
& & & $(0.015)$ & $(0.020)$ \\
Constant & -0.155 & -0.036 & $-0.387 * *$ & 0.119 \\
\hline Periods & $(0.103)$ & $(0.127)$ & $(0.153)$ & $(0.344)$ \\
Observations & $1-24$ & $13-24$ & $1-24$ & $13-24$ \\
Number of Buyers & 2,855 & 1,432 & 2,855 & 1,432 \\
\hline \hline
\end{tabular}

Notes: The dependent variable in all models takes on value 1 if a buyer purchased a fair product and 0 if the buyer purchased a harmful product; we omit the 1 percent of cases in which the consumer purchased no product. Treatment Concentrated serves as the omitted category in all regression models. "Diffused" is a binary variable taking on value 1 for data generated in treatment Diffused. Models 1 and 3 report the results for all 24 periods, such that "Period" takes on integer values between 1 and 24. Models 2 and 4 report the results for the last 12 periods only, such that "Period" takes on integer values between 13 and 24. The table reports raw probit coefficients. All standard errors (in parentheses) are clustered at the market level; *** $\mathrm{p}<0.01, * * \mathrm{p}<0.05, * \mathrm{p}<0.1$.

Hence, while our non-parametric and regression analyses both point to lower concern for the negative social impact of the externality when the impact of a harmful product is diffused among several third parties, this effect is moderate in magnitude and not robustly statistically significant. Moreover, behavior in both treatments remains far from the predictions derived from traditional theory under the assumption of narrow self-interest, which predicts a zero market share for the harmful product.

We next study who bears the burden of the cost of producing the fair product. Figure 2 presents the mean of the endogenously determined prices for both types of products. The figure 
reveals that fair products persistently trade at higher prices than harmful products in both treatments, reflecting the higher production cost associated with fair products. The price premium-i.e., the difference between the mean price of the fair product and mean price of the harmful one-is equal to 16.32 in treatment Concentrated and 14.48 in treatment Diffused. ${ }^{5}$ This indicates that most of the cost of eliminating the negative externality - a cost equal to 20-is borne by buyers. ${ }^{6}$ Figure 2 further reveals that the prices of both types of products are very similar in both treatments. There are no significant differences between the two treatments for prices of the same product type when averaged at the market level (Wilcoxon rank-sum test, $p=0.33$ for the fair product and $p=0.88$ for the harmful product, two-sided).

Figure 2 - Prices of each type of product (Concentrated vs. Diffused)

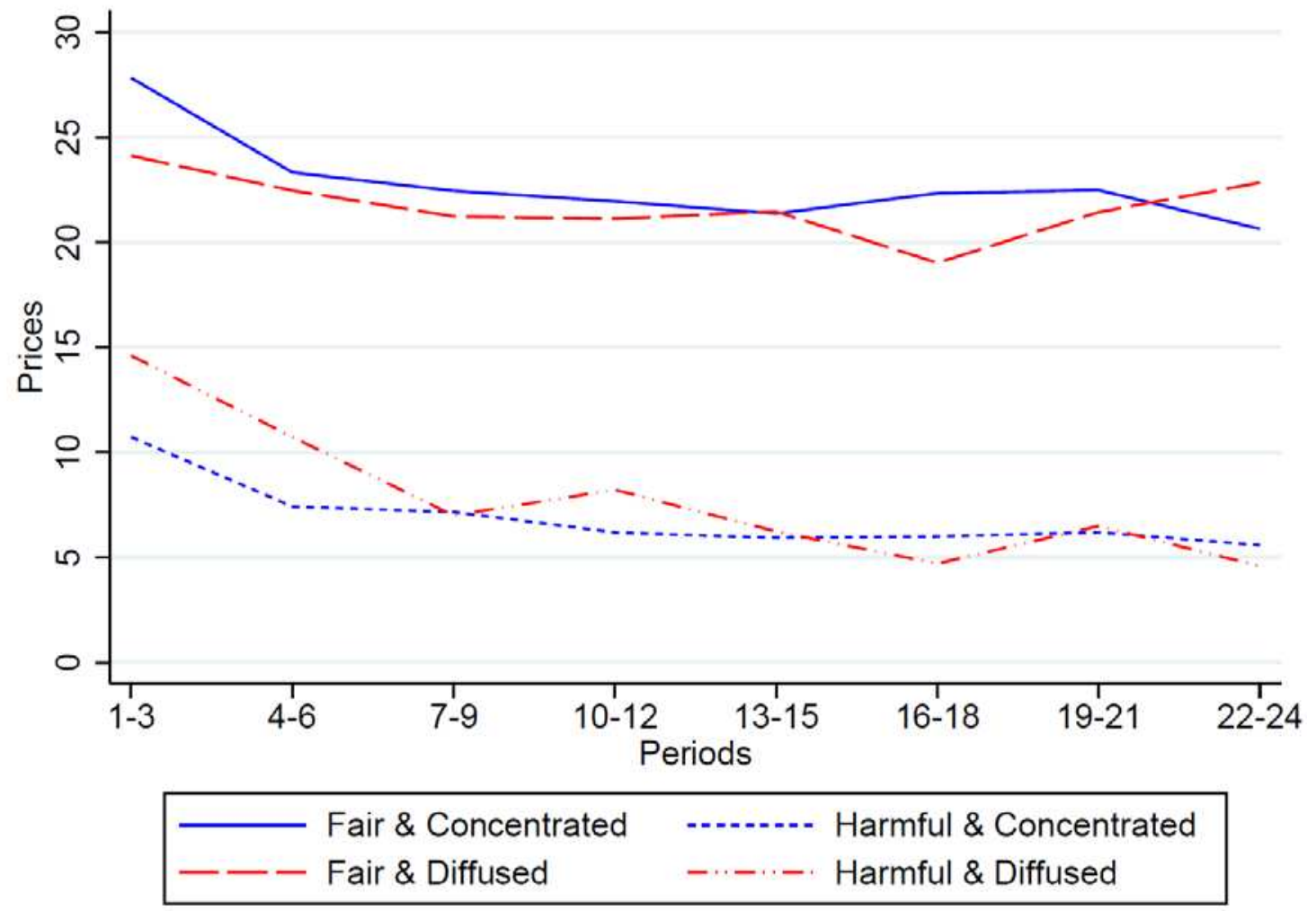

\footnotetext{
${ }^{5}$ We calculate the average price paid for each type of product in all periods where both types were bought and report the difference of these prices averaged over all periods in all markets. We thus neglect prices in cases where only one type of product was bought in a given period and market. Simply calculating the respective average prices of all fair and of all unfair products bought in all periods and markets and taking the difference yields very similar price premiums of 15.21 and 13.36, respectively, for treatment Concentrated and treatment Diffused.

${ }^{6}$ Note that in 5 percent of cases, sellers offered the fair product at prices below its production cost, perhaps out of a desire to partially subsidize such products. Buyers often accepted these offers, driving down average market prices. This yields a case in Figure 2 where the average price is below the production cost of 20.
} 


\subsection{Additional treatment with concentrated harm}

Recall that, in treatment Concentrated, a buyer's product purchases impact a randomly determined third party, with a new third party selected in every period. This could, in principle, be perceived by the subjects as a negative impact that is diffused in expectation. Therefore, we conduct an additional treatment, Concentrated \& Fixed, in which, for each buyer, a third party is selected at the beginning of the experiment so that the buyer's product purchases impact the same third party in every period. Thus, in this treatment, concentrated harm is entirely focused upon one other individual. $^{7}$

Figure 3 shows that the market shares in treatments Concentrated \& Fixed and Concentrated are very similar, 45 percent vs. 43 percent, respectively. A Wilcoxon rank-sum test (two-sided) confirms that the difference is not statistically significant, at either the market $(p=0.97)$ or buyer $(p=0.79)$ level. $^{8}$

Figure 3 - Market shares of fair products (Concentrated vs. Concentrated \& Fixed)

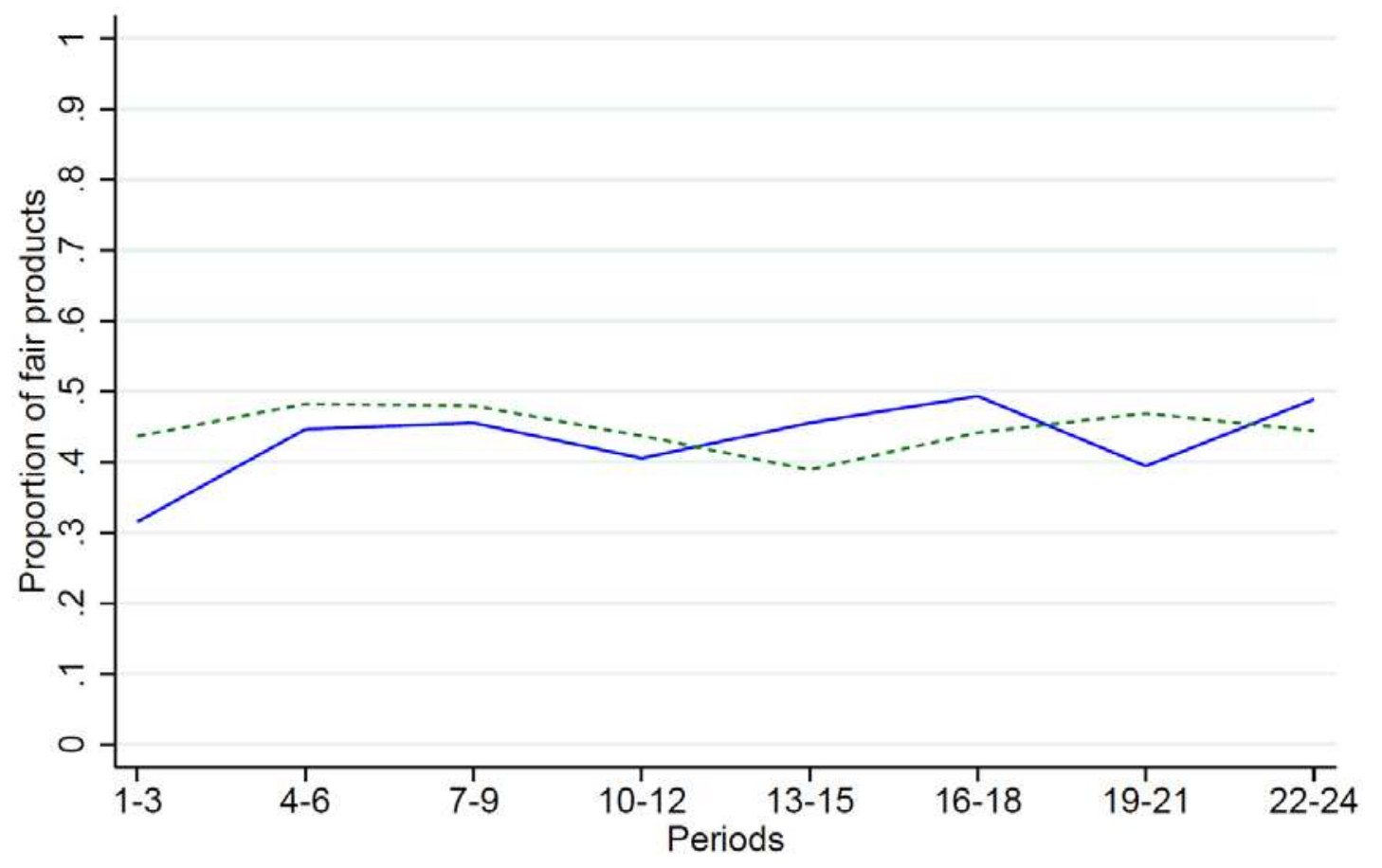

Concentrated ------- Concentrated \& Fixed

\footnotetext{
${ }^{7}$ We thank an anonymous referee for suggesting this treatment.

${ }^{8}$ The prices of fair and harmful product types do not differ much between the two treatments (shown in Figure A1 in the appendix). These differences are not statistically significant, when aggregated at the market level (Wilcoxon ranksum test, $p=0.45$ for the fair product and $p=0.26$ for the harmful one, two-sided).
} 
These results indicate that making a more permanent and salient match between a market participant and the individual impacted by the market actor's behavior does not significantly affect the degree to which market outcomes reflect a concern for negative externalities. Hence, moving further in the direction of more concentrated harm does not appear to have a strong impact on the extent to which subjects demonstrate concern for the external impacts of their market activity.

\subsection{Individual behavior of buyers}

We next consider more closely the individual behavior of buyers. Figure 4 shows the empirical cumulative distributions (CDFs) of individual buyer behavior over the course of the experiment for each of the three treatments. A buyer's behavior refers to that subject's frequency of fair product purchases over the course of the 24 periods of the experiment; a buyer who never bought a fair product corresponds to a frequency of 0 , while a buyer who always did so corresponds to a frequency of 1 . Thus, for example, the dotted line shows that slightly over 10 percent of buyers never bought a fair product in treatment Concentrated \& Fixed. The CDFs reveal substantial heterogeneity and dispersion in buyers' behavior across all the treatments. Moreover, only a minority of buyers consistently bought either the unfair or the fair product—only about 5, 7 and 12 percent of buyers always bought the unfair product in Diffused, Concentrated and Concentrated \& Fixed, respectively, and about 7, 17 and 8 percent always bought the unfair product, respectively. While these numbers and the distributions in Figure 1 differ slightly, two-sample Kolmogorov-Smirnov tests cannot reject the equality of distributions when comparing either treatments Concentrated and Diffused ( $p=0.304)$ or Concentrated and Concentrated \& Fixed $(p=0.304)$, and there is only a marginally statistically significant difference between the distributions when comparing Diffused and Concentrated \& Fixed $(p=0.085)$. 


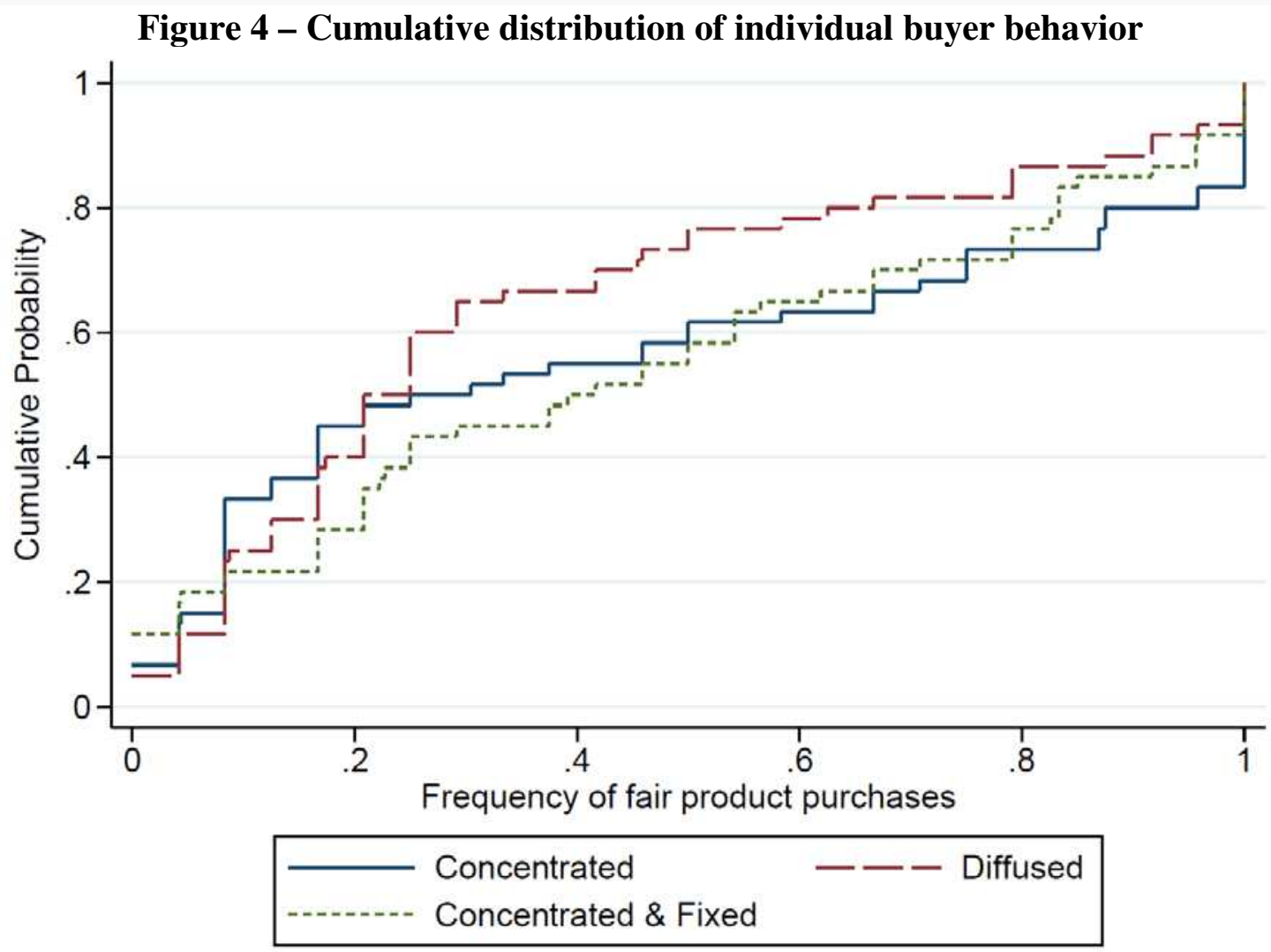

Finally, to further investigate buyer behavior, we estimate parameters for a utility model that incorporates buyers' concerns for their own earnings and for social impact. More specifically, the basic model is:

$$
u_{t k}=\theta x_{t k}+\gamma y_{t k}+\varepsilon_{t k}
$$

corresponding to a buyer's utility from a potential choice of a product $k$ in a period $t$. In this utility framework, $x_{t k}$ equals a buyer's own payoff from that product (determined by a product's price) and $y_{t k}$ equals the social cost of that product (either 0 or 60). Following McFadden (1974), $\varepsilon_{t k}$ is an extreme-value (logit) error. 
Table 2 - Utility model

\begin{tabular}{lccccc}
\hline \hline & Concentrated & Diffused & $\begin{array}{c}\text { Concentrated } \\
\text { \& Fixed }\end{array}$ & $\begin{array}{c}\text { All } \\
\text { treatments }\end{array}$ & $\begin{array}{c}\text { All } \\
\text { treatments }\end{array}$ \\
& $(1)$ & $(2)$ & $(3)$ & $(4)$ & $(5)$ \\
\hline Buyer Earnings $(\theta)$ & $0.170^{* * *}$ & $0.178^{* * *}$ & $0.210^{* * *}$ & $0.184^{* * *}$ & $0.183^{* * *}$ \\
& $(0.023)$ & $(0.028)$ & $(0.031)$ & $(0.016)$ & $(0.016)$ \\
Social Cost $(\gamma)$ & $-0.038^{* * *}$ & $-0.027^{* * *}$ & $-0.052^{* * *}$ & $-0.041^{* * *}$ & $-0.042^{* * *}$ \\
& $(0.008)$ & $(0.007)$ & $(0.013)$ & $(0.006)$ & $(0.006)$ \\
Social Cost X Diffused & & & & 0.012 & $0.014^{*}$ \\
& & & & $(0.009)$ & $(0.008)$ \\
Social Cost X Fixed & & & & -0.004 & \\
\hline Observations & $7^{\prime} 200$ & $7^{\prime} 200$ & $7^{\prime} 200$ & $21^{\prime} 600$ & $21^{\prime} 600$ \\
Cases & $1^{\prime} 440$ & $1^{\prime} 440$ & $1^{\prime} 440$ & $4^{\prime} 320$ & $4^{\prime} 320$ \\
\hline \hline
\end{tabular}

Notes: "Fixed" and "Diffused" are binary variables, taking on value 1 for data generated in treatments Concentrated \& Fixed and Diffused, respectively. Treatment Concentrated serves as the omitted category in model 4. Treatments Concentrated and Concentrated \& Fixed serve as the omitted categories in model 5, since we do not include "Fixed" in this specification. Standard errors, clustered at the market level, in parentheses; *** $\mathrm{p}<0.01, * * \mathrm{p}<0.05, * \mathrm{p}<0.1$.

Models 1 to 3 in Table 2 show that, in all treatments, buyers care about their own earnings—reflected in the positive coefficient for "Buyer Earnings." They also care about lowering social costs—reflected in the negative coefficient for "Social Cost." Beyond the sign of these two coefficients, we can also infer relative concern for own payoffs and for social impact from the coefficients' relative magnitudes. Specifically, their ratio indicates the relative concern that the average buyer places on her own earnings versus the social impact of her market behavior. For example, in model 1, this ratio is -4.47 , suggesting that, on average, buyers in the Concentrated treatment are willing to sacrifice one unit of payoff to reduce the social cost by roughly 4.5 units. Consistent with Figure 1, this measure of social concern is slightly lower in treatment Diffused i.e., the ratio is -6.59. Moreover, social concern is similar in treatments Concentrated (-4.47) and Concentrated \& Fixed (-4.04), which is consistent with Figure 3. In model 4, we test whether the difference in concern for social costs differs between the treatments when the effects are estimated jointly. The interaction terms "Social Cost X Diffused" and "Social Cost X Fixed" are statistically insignificant, indicating that neither change from treatment Concentrated, which corresponds to 
the scope of externalities in BWY and serves as omitted category in model 4, yields a substantial impact on buyers' social concern. ${ }^{9}$ In model 5, we omit the interaction "Social Cost X Fixed" so that "Social Cost X Diffused" picks up the difference between treatment Diffused and both treatments with concentrated harm-i.e., in this model, Concentrated and Concentrated \& Fixed represent the omitted category. We find that "Social Cost X Diffused" is marginally statistically significant, at the ten percent level. Thus, when we pool the two treatments with concentrated harm, buyers appear to exhibit a higher concern for social impact when the harm is diffused. However, as in our earlier analysis, this treatment effect is not robustly statistically significant.

\section{Conclusions}

When present, the external effects of market activity potentially constitute a major source of societal inefficiency. Understanding the conditions under which socially responsible behavior by market actors can yield a remedy, at least partially, is thus of high interest. This paper focuses on one particular, potentially important, driver of socially responsible market behavior: the scope of externalities.

We find that market participants' concern for social responsibility-i.e., trading more costly but less harmful products-is influenced slightly by the degree to which negative externalities are borne by a single person or are diffused over several people, holding constant the total impact. Diffused market impacts elicit somewhat less concern, though the magnitude of this difference is of moderate magnitude and its statistical significance is not robust. Importantly, even when the social harm is diffused, the market share of the fair product stabilizes at a substantial level—34 percent. Thus, while we do find some evidence that market participants respond to the scope of an externality, they appear to primarily weigh the total harm produced by their actions, rather than disproportionately weighting the impact felt by any single person.

An additional contribution of this paper is to address a potential explanation for divergent experimental findings concerning pro-sociality in markets. Plott (1983), in one of the first studies to investigate the voluntary internalization of externalities in an experimental market, observed markets to behave as if there were no externalities at all-suggesting that market outcomes are

\footnotetext{
${ }^{9}$ If we, instead, use treatment Concentrated \& Fixed as the omitted category in model (4), the coefficient Social Cost $X$ Diffused is positive and marginally statistically significant $(\mathrm{p}<0.1)$.
} 
accurately predicted by the traditional model, even in the presence of externalities. However, the results of more recent experimental contributions often yield apparent significant concern for the negative external impacts of market behavior (e.g., Danz et al. 2012, Falk and Szech 2013, Bartling et al. 2015, Irlenbusch and Saxler 2015, Kirchler et al. 2015, Pigors and Rockenbach 2016, Sutter et al. 2016). For instance, Bartling et al. (BWY) find substantial market shares of a "fair" product that does not produce a negative externality but is more expensive to produce than an otherwise identical "harmful" product that imposes a negative externality on a third party. That is, in BWY's experimental markets, buyers and sellers are willing to forgo money in order to avoid imposing harm on other subjects-a kind of pro-social behavior that was largely absent in Plott's earlier market experiment. While the externality in Plott is diffused and trade exerts a small per capita impact on many individuals, in BWY the negative social impact is concentrated on a single individual. Our data suggests that this difference does not account for why BWY find prevalent concern for social impact among market actors, while Plott finds little evidence of such concern.

Of course, there remain many open questions regarding the conditions under which market participants will voluntarily internalize the external impacts of their market activity. For instance the current paper does not provide an answer to the question of why market participants in Plott's earlier design entirely disregard the externality, while market participants in BWY's design do not. Several possibilities remain. One such possibility is the market design: Plott used a double-auction market mechanism but BWY and our present study employ a posted-offer market. ${ }^{10}$ Another possibility deals with who is impacted by the externalities produced by market activity-market actors, as in Plott's study, or passive third parties, as in BWY. Exploring each of these possible factors is beyond the scope of the current paper. We thus leave it to future research to further examine the determinants of socially responsible market behavior and thereby shed further light on the important issue of when markets actors respond to the presence of negative externalities, and when they do not.

\footnotetext{
${ }^{10} \mathrm{We}$ can, however, argue that it is unlikely that increased competition in double-auction markets alone is responsible for the difference. BWY study a treatment in which there is increased competition between firms, relative to the baseline design, and find that socially responsible behavior is not less prevalent in this treatment. Moreover, the design we employ in this paper also increases competition among sellers, relative to BWY (see footnote 4), and we find virtually no difference in the market shares of fair products despite the higher production cost in the current study.
} 


\section{References}

Barrios-Guerra, C.A., "Mercury contamination in Chile: a chronicle of a problem foretold," (2004), Reviews of Environmental Contamination and Toxicology, 1-19, Springer New York.

Bartling, B., R. Weber, and L. Yao, “Do Markets Erode Social Responsibility?” Quarterly Journal of Economics, 130.1 (2015), 219-266.

Bénabou, R., and J. Tirole, “Individual and Corporate Social Responsibility,” Economica, 77 (2010), $1-19$.

Block, O., I. Baetge, and A. Nicklisch, "hroot: Hamburg registration and organization online tool," European Economic Review, 71 (2014), 117-120.

Danz, D., D. Engelmann, and D. Kübler, "Do Legal Standards Affect Ethical Concerns of Consumers? An Experiment on Minimum Wages," University of Mannheim, Department of Economics, Working Paper 12-3, 2012.

Falk, A., and N. Szech, "Morals and Markets," Science, 340 (2013), 707-711.

Fischbacher, U., "z-Tree: Zurich toolbox for ready-made economic experiments," Experimental Economics, 10.2 (2007), 171-178.

Irlenbusch, B., and D. Saxler, "Social Responsibility in Market Interaction," (2015), IZA Discussion Paper No. 9240.

Harada, M, "Minamata disease: methylmercury poisoning in Japan caused by environmental pollution," (1995), Critical Reviews in Toxicology, 25(1), pp.1-24.

Kirchler, M., J. Huber, M. Stefan, and M. Sutter. "Market Design and Moral Behavior," Management Science, 62.9 (2015), 2615-2625.

Pigors, M., and B. Rockenbach. "Consumer Social Responsibility," forthcoming in Management Science (2016).

Plott, C. R., "Externalities and Corrective Policies in Experimental Markets,” Economic Journal, 93 (1983), 106-127.

Schumacher, H., I. Kesternich, M. Kosfeld, and J. Winter: “One, Two, Many - Insensitivity to Group Size in Games with Concentrated Benefits and Dispersed Costs," forthcoming in Review of Economic Studies (2016). 
Slovic, P., "If I look at the mass I will never act: Psychic numbing and genocide," Judgment and Decision Making, 2.2 (2007), 79-95.

Small, D. A., and G. Loewenstein, "Helping a victim or helping the victim: Altruism and identifiability," Journal of Risk and Uncertainty, 26.1 (2003), 5-16.

Small, D. A., G. Loewenstein, and P. Slovic, "Sympathy and callousness: The impact of deliberative thought on donations to identifiable and statistical victims," Organizational Behavior and Human Decision Processes, 102.2 (2007), 143-153.

Smith, V. L., "An Experimental Study of Competitive Market Behavior." Journal of Political Economy, 70.2 (1962), 111-137.

Sutter, M., J. Huber, M. Kirchler, and M. Stefan, "Where to Look for the Morals in Markets?" (2016), IZA Discussion Paper No. 10105. 


\section{Appendix A - Additional Figures}

Figure A1 - Prices of each type of products (Concentrated vs. Concentrated \& Fixed)

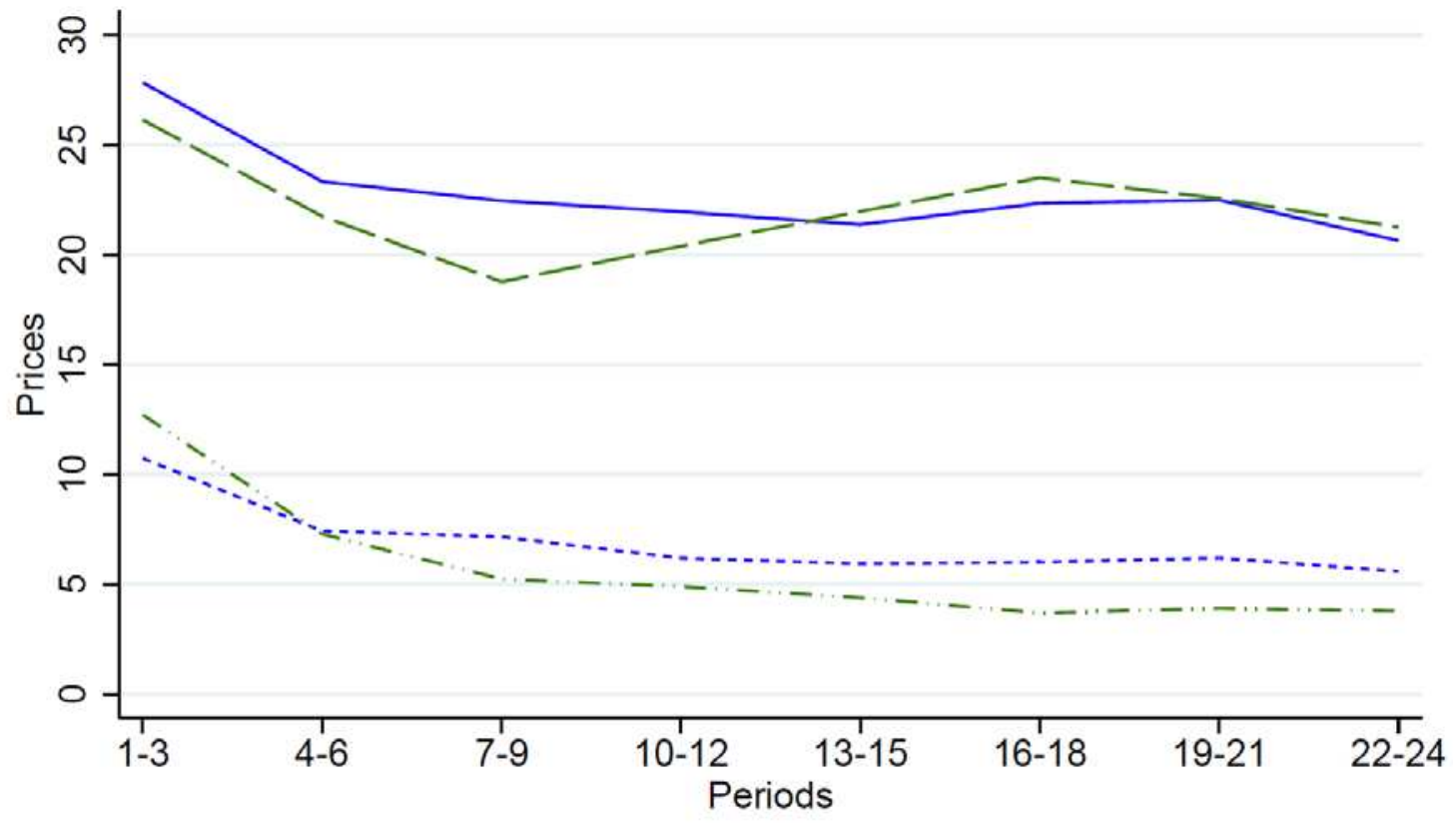

$$
\begin{aligned}
& \text { - Fair \& Concentrated _........ Harmful \& Concentrated } \\
& \text { - - Fair \& Fixed } \quad-\cdots-\cdots-\text {. Harmful \& Fixed }
\end{aligned}
$$

Fixed refers to the treatment Concentrated \& Fixed 


\section{Appendix B - Experimental Instructions}

\section{B.1. Treatment Concentrated}

\section{General instructions}

We are pleased to welcome you to this economic study.

If you read the following instructions carefully, you can - depending on your decisions and/or those of the other participants - earn money in addition to the $\mathbf{1 5}$ Swiss francs that you receive as an initial participation payment. It is thus very important that you read the instructions carefully. If you have any questions, please contact us.

Communication with the other participants is strictly forbidden during the study. Violation of this rule will lead to exclusion from the study and loss of all of the associated payments.

During the study, we will not speak of Swiss francs, but of points. Your entire income will thus first be calculated in points. The points you earn during the study will be converted to Swiss francs at the end of the study. The following conversion rate applies:

\section{0 points $=2$ Swiss francs}

At the end of today's study, you will receive the number of points earned during the study plus the initial participation payment of 15 Swiss francs in cash.

We will explain the exact procedure of the study on the next pages. For the sake of simplicity, we will always use male forms for participants; the instructions also obviously refer to female participants. 


\section{The study}

There are three types of participants in this study: Participants A, B, and C. Participants in this study are divided into groups of 16 people. There are 4 Participants A, 6 Participants B, and 6 Participants $\mathrm{C}$ in each group.

Participants A are sellers, Participants B are buyers. Participants C can neither sell nor buy, but they can incur losses due to the transactions between the Participants $A$ and $B$.

The study lasts for 24 periods. In each period, each Participant A can sell only one kind of product. Participants A thereby determine the type and the price of the product they would like to offer.

- There are two types of products:

1. "Products with no effect on Participant C' and

2. "Products with a loss for Participant C."

- Every value from 0 up to and including 50 can be selected as a price.

The production costs for Participants A for a "product with no effect on Participant C" amount to 20 points. Participants A bear no cost (0 points) for the production of a "product with a loss for Participant C."

The value of a product for a Participant B is always $\mathbf{5 0}$ points, regardless of what type of product it is.

The 6 Participants B see the sales offers made by the 4 Participants A (the price and the type of product) and can only accept one offer each. This means that a maximum of 6 products can be sold in a given period. These products can be sold by the same Participant A or by different ones such that each Participant A can sell from 0 to 6 products.

In each period, each of the 6 Participants $B$ will be randomly assigned to one of the 6 Participants C. If a Participant B purchases a "product with a loss for Participant C," the matched Participant $\mathrm{C}$ incurs a loss of $\mathbf{6 0}$ points. If a Participant $\mathrm{B}$ purchases a "product with no effect on Participant C" or no product at all, the matched Participant $\mathrm{C}$ incurs no loss.

You will see whether you are Participant A, B, or $\mathrm{C}$ on your screen at the beginning of the study. Your role as Participant A, B, or $\mathrm{C}$ will remain the same during the entire study. 
In each period, each Participant A, B, and C initially receives an endowment of 100 points. The payment in points of Participant A (seller), Participant B (buyer), and Participant C in a period are thus determined as follows:

\section{Participant A's payment:}

- If Participant A's sales offer is accepted by at least one Participant B:

$$
100+(\text { price of the product - production cost }) * \text { quantity of product sold }
$$

where the production cost amounting to 20 points is incurred only with a "product without effect on Participant C." The production cost for a "product with a loss for Participant C", amounts to 0 .

- If no Participant B accepts Participant A's sales offer: 100

\section{Participant B's payment:}

- If Participant B accepts a sales offer:

$$
100+50 \text { - price of the product }
$$

- If Participant B does not accept a sales offer: 100

\section{Participant C's payment:}

- If the randomly assigned Participant B chooses a "product with loss for Participant C":

$$
100-60=40
$$

- If the randomly assigned Participant B chooses a "product without effect on Participant C" or does not purchase a product: 100 


\section{Procedures on the computer:}

Participants A enter their sales offers on the following screen in each period:

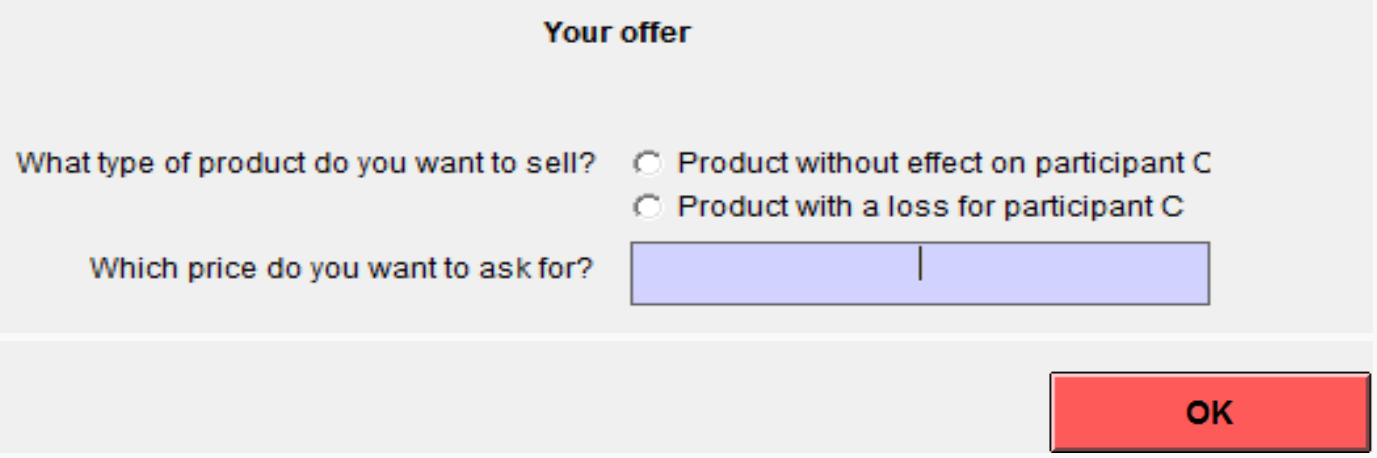

Participant A must indicate whether he wants to sell a "product without effect on Participant C" or a "product with a loss for Participant C." To do this, he must click on the corresponding type of product.

Furthermore, Participant A must indicate the price he wants to request for the product. The corresponding number must be entered in the box. All integers from 0 up to and including 50 are possible.

Once a Participant A has made his decisions, he must click on the OK button at the lower righthand side. The type of product and the price can be changed until the OK button is clicked.

Once all 4 Participants A have made their sales offers, Participants A will see the sales offers (the price and the type of product) of all of the other Participants A in a table. Here is how the table will look like:

\begin{tabular}{|c|c||c|}
\hline Price of the product & Type of the product & Quantity of products sold \\
\hline $\begin{array}{c}\text { This is where Participants A see } \\
\text { the price of the product for every } \\
\text { sales offer }\end{array}$ & $\begin{array}{c}\text { This is where Participants A see } \\
\text { the type of product for every } \\
\text { sales offer }\end{array}$ & $\begin{array}{c}\text { This is where Participants A see } \\
\text { the quantity of products sold for } \\
\text { every sales offer }\end{array}$ \\
\hline
\end{tabular}

The participant's own sales offer is always marked in blue. Participants A can always see in the column on the right how many Participants B accept each of the offers, i.e. quantity of the product sold by each of the four Participants A.

Participants B will make their decisions by selecting from one of the four offers, or deciding to not purchase a product. Once all Participants B have made their decisions, each Participant A will learn of his own payment. If his offer is accepted, Participant A will also learn Participant B's payment and the payment of the corresponding Participant $\mathrm{C}$. 
Participants B can see the sales offers on a screen like the one below in each period:

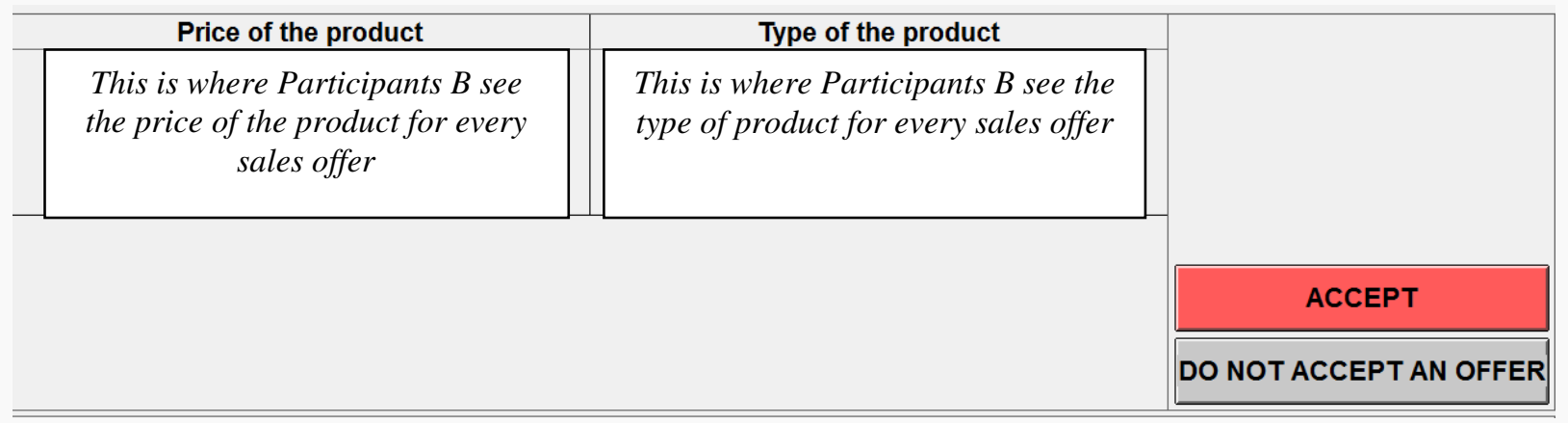

The prices appear in the left column of the table, and the type of product appears in the right column. Each offer is always in a separate row. In order to accept an offer, Participant B must click on the corresponding row with the mouse. The marked row will then appear with a blue background.

- In order to accept the offer marked in blue, you must click on the ACCEPT button.

The choice of offer can be changed until the ACCEPT button is clicked.

If a Participant B does not want to accept an offer, he must click on the DO NOT ACCEPT AN OFFER button. Even if a row had already been marked, all offers will be declined if the DO NOT ACCEPT AN OFFER is clicked.

When all Participants B have made their decisions, each Participant B will learn of his own payment and that of his assigned Participant $\mathrm{C}$.

Participants $\mathbf{C}$ cannot make any decisions during this study. We ask Participants $\mathrm{C}$, however, to indicate in each period their expectations about the behaviors of Participants A and B.

When all Participants A and B have made their decisions, Participants $\mathrm{C}$ will learn of their own earnings, which are entirely dependent on the decisions of Participants A and B.

After all participants have been informed about their payments in a period, the next period will begin. 
To all participants:

Your earnings in this study are the payments out of one randomly selected period. That is, the computer will randomly select one period at the end of the study to count for payment.

Because you do not know which period the computer will randomly select, you must consider your decisions in each of the 24 periods very carefully.

At the end of the study, the corresponding point amount will be converted to Swiss francs and paid in cash to you together with the initial participation payment.

Do you have any further questions? If yes, please raise your hand. We will come to you at your workplace. Otherwise, we ask you to answer the Control Questions that you find on your screen, once you click the "OK" button. 


\section{B.2. Treatment Diffused}

\section{General instructions}

We are pleased to welcome you to this economic study.

If you read the following instructions carefully, you can - depending on your decisions and/or those of the other participants - earn money in addition to the $\mathbf{1 5}$ Swiss francs that you receive as an initial participation payment. It is thus very important that you read the instructions carefully. If you have any questions, please contact us.

Communication with the other participants is strictly forbidden during the study. Violation of this rule will lead to exclusion from the study and loss of all of the associated payments.

During the study, we will not speak of Swiss francs, but of points. Your entire income will thus first be calculated in points. The points you earn during the study will be converted to Swiss francs at the end of the study. The following conversion rate applies:

\section{0 points $=2$ Swiss francs}

At the end of today's study, you will receive the number of points earned during the study plus the initial participation payment of 15 Swiss francs in cash.

We will explain the exact procedure of the study on the next pages. For the sake of simplicity, we will always use male forms for participants; the instructions also obviously refer to female participants. 


\section{The study}

There are three types of participants in this study: Participants A, B, and C. Participants in this study are divided into groups of 16 people. There are 4 Participants A, 6 Participants B, and 6 Participants $\mathrm{C}$ in each group.

Participants A are sellers, Participants B are buyers. Participants C can neither sell nor buy, but they can incur losses due to the transactions between the Participants $A$ and $B$.

The study lasts for 24 periods. In each period, each Participant A can sell only one kind of product. Participants A thereby determine the type and the price of the product they would like to offer.

- There are two types of products:

\section{3. "Products with no effect on Participants C" and}

\section{4. "Products with a loss for Participants C."}

- Every value from 0 up to and including 50 can be selected as a price.

The production costs for Participants A for a "product with no effect on Participants C" amount to 20 points. Participants A bear no cost (0 points) for the production of a "product with a loss for Participants C."

The value of a product for a Participant B is always $\mathbf{5 0}$ points, regardless of what type of product it is.

The 6 Participants B see the sales offers made by the 4 Participants A (the price and the type of product) and can only accept one offer each. This means that a maximum of 6 products can be sold in a given period. These products can be sold by the same Participant A or by different ones such that each Participant A can sell from 0 to 6 products.

If a Participant B purchases a "product with a loss for Participants C," each of the 6 Participants

$\mathrm{C}$ incurs a loss of 10 points. This means a combined total loss of 60 points for all 6 Participants C. If a Participant B purchases a "product with no effect on Participants C" or no product at all, Participants $\mathrm{C}$ do not incur a loss of 10 points each.

You will see whether you are Participant A, B, or $\mathrm{C}$ on your screen at the beginning of the study. Your role as Participant A, B, or $\mathrm{C}$ will remain the same during the entire study. 
In each period, each Participant A, B, and C initially receives an endowment of 100 points. The payments in points of Participant A (seller), Participant B (buyer), and Participant C in a period are thus determined as follows:

\section{Participant A's payment:}

- If Participant A's sales offer is accepted by at least one Participant B:

$$
100+(\text { price of the product - production cost }) * \text { quantity of product sold }
$$

where the production cost amounting to 20 points is incurred only with a "product without effect on Participants C." The production cost for a "product with a loss for Participants C" amounts to 0 .

- If no Participant B accepts Participant A's sales offer: 100

\section{Participant B's payment:}

- If Participant B accepts a sales offer:

$$
100+50 \text { - price of the product }
$$

- If Participant B does not accept a sales offer: 100

\section{Participant C's payment:}

- If at least one Participant B chooses a "product with loss for Participants C":

$$
100 \text { - } 10 \text { * quantity of "product with loss for Participants C" bought }
$$

Note that this means that each Participant $C$ can end up with a payment of either 40, 50, $60,70,80,90$ or 100, depending on how many Participants B choose a "product with loss for Participants C."

- If all Participants B choose a "product without effect on Participants C" or do not purchase a product: 100 


\section{Procedures on the computer:}

Participants A enter their sales offers on the following screen in each period:

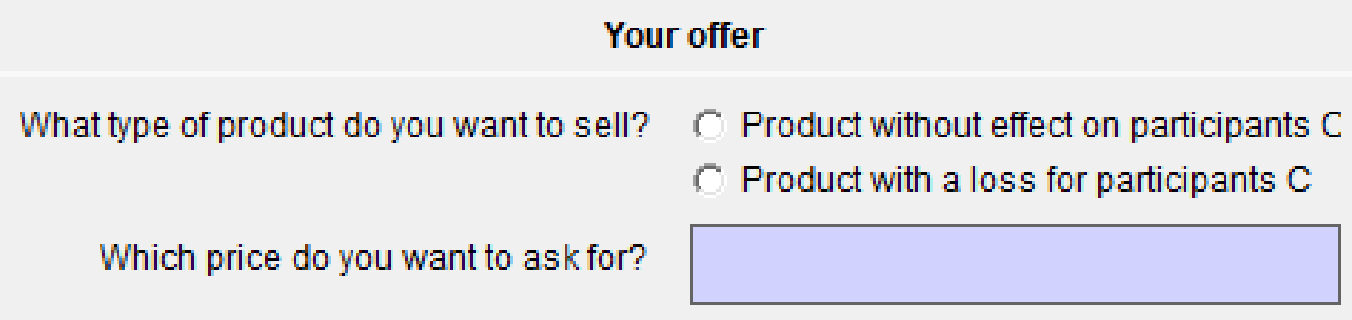

OK

Participant A must indicate whether he wants to sell a "product without effect on Participants C" or a "product with a loss for Participants C." To do this, he must click on the corresponding type of product.

Furthermore, Participant A must indicate the price he wants to request for the product. The corresponding number must be entered in the box. All integers from 0 up to and including 50 are possible.

Once a Participant A has made his decisions, he must click on the OK button at the lower righthand side. The type of product and the price can be changed until the OK button is clicked.

Once all 4 Participants A have made their sales offers, Participants A will see the sales offers (the price and the type of product) of all of the other Participants A in a table. Here is how the table will look:

\begin{tabular}{|c|c||c|}
\hline Price of the product & Type of the product & Quantity of products sold \\
\hline $\begin{array}{c}\text { This is where Participants A see } \\
\text { the price of the product for every } \\
\text { sales offer }\end{array}$ & $\begin{array}{c}\text { This is where Participants A see } \\
\text { the type of product for every } \\
\text { sales offer }\end{array}$ & $\begin{array}{c}\text { This is where Participants A see } \\
\text { the quantity of products sold for } \\
\text { every sales offer }\end{array}$ \\
\hline
\end{tabular}

The participant's own sales offer is always marked in blue. Participants A can always see in the column on the right how many Participants B accept each of the offers, i.e. quantity of the product sold by each of the four Participants A.

Participants B will make their decisions by selecting from one of the four offers, or deciding to not purchase a product. Once all Participants B have made their decisions, each Participant A will learn of his own payment. If his offer is accepted, Participant A will also learn Participant B's payment and the effect of the product on the payments of all 6 Participants C. 
Participants B can see the sales offers on a screen like the one below in each period:

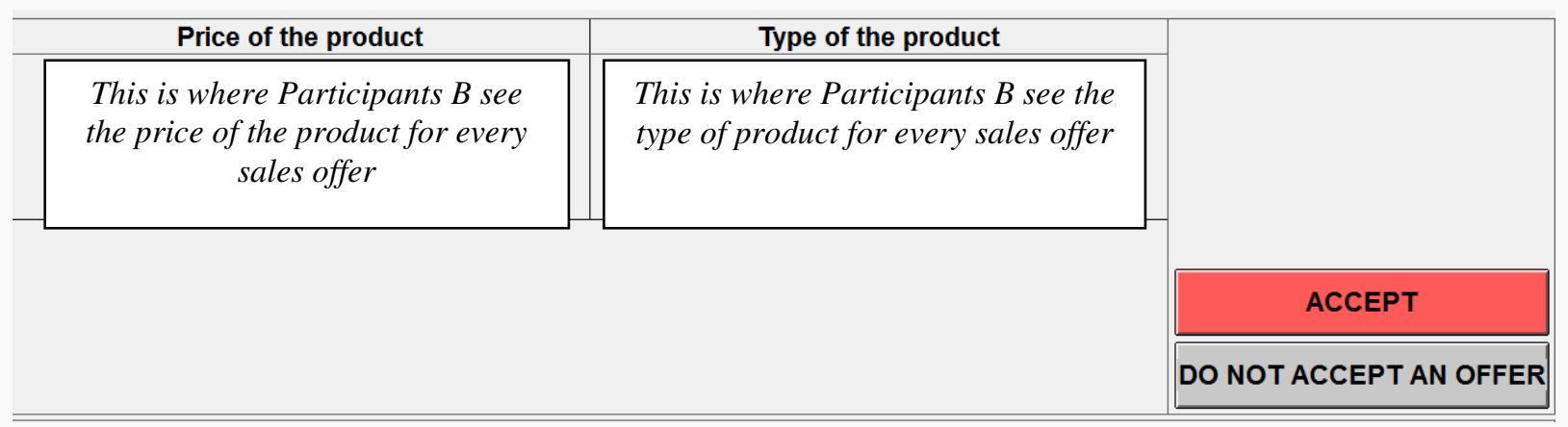

The prices appear in the left column of the table, and the type of product appears in the right column. Each offer is always in a separate row. In order to accept an offer, Participant B must click on the corresponding row with the mouse. The marked row will then appear with a blue background.

- In order to accept the offer marked in blue, you must click on the ACCEPT button.

The choice of offer can be changed until the ACCEPT button is clicked.

If a Participant B does not want to accept an offer, he must click on the DO NOT ACCEPT AN OFFER button. Even if a row had already been marked, all offers will be declined if the DO NOT ACCEPT AN OFFER is clicked.

When all Participants B have made their decisions, each Participant B will learn of his own payment and the effect of his decision on the payments of all 6 Participants $\mathrm{C}$.

Participants $\mathbf{C}$ cannot make any decisions during this study. We ask Participants $\mathbf{C}$, however, to indicate in each period their expectations about the behaviors of Participants A and B.

When all Participants A and B have made their decisions, Participants C will learn of their own earnings, which are entirely dependent on the decisions of Participants A and B.

After all participants have been informed about their payments in a period, the next period will begin. 
To all participants:

Your earnings in this study are the payments out of one randomly selected period. That is, the computer will randomly select one period at the end of the study to count for payment.

Because you do not know which period the computer will randomly select, you must consider your decisions in each of the 24 periods very carefully.

At the end of the study, the corresponding point amount will be converted to Swiss francs and paid in cash to you together with the initial participation payment.

Do you have any further questions? If yes, please raise your hand. We will come to you at your workplace. Otherwise, we ask you to answer the Control Questions that you find on your screen, once you click the "OK" button. 